
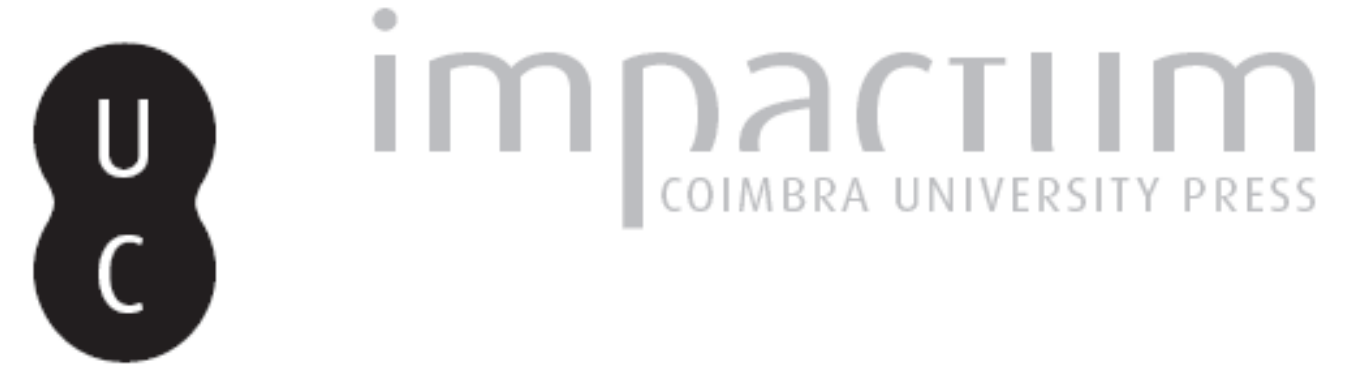

\title{
A experiência colonial e as raízes do pensamento social brasileiro: Oliveira Vianna e Sérgio Buarque de Holanda
}

Autor(es): $\quad$ Gomes, Ângela de Castro

Publicado por: $\quad \begin{aligned} & \text { Instituto de História Económica e Social, Faculdade de Letras da } \\ & \text { Universidade de Coimbra }\end{aligned}$

URL

persistente:

DOI: $\quad$ DOI:http://dx.doi.org/10.14195/0870-4147_41_11

Accessed : $\quad$ 26-Apr-2023 15:00:35

A navegação consulta e descarregamento dos títulos inseridos nas Bibliotecas Digitais UC Digitalis, UC Pombalina e UC Impactum, pressupõem a aceitação plena e sem reservas dos Termos e Condições de Uso destas Bibliotecas Digitais, disponíveis em https://digitalis.uc.pt/pt-pt/termos.

Conforme exposto nos referidos Termos e Condições de Uso, o descarregamento de títulos de acesso restrito requer uma licença válida de autorização devendo o utilizador aceder ao(s) documento(s) a partir de um endereço de IP da instituição detentora da supramencionada licença.

Ao utilizador é apenas permitido o descarregamento para uso pessoal, pelo que o emprego do(s) título(s) descarregado(s) para outro fim, designadamente comercial, carece de autorização do respetivo autor ou editor da obra.

Na medida em que todas as obras da UC Digitalis se encontram protegidas pelo Código do Direito de Autor e Direitos Conexos e demais legislação aplicável, toda a cópia, parcial ou total, deste documento, nos casos em que é legalmente admitida, deverá conter ou fazer-se acompanhar por este aviso.

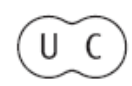





\title{
A experiência colonial e as raízes do pensamento social brasileiro: Oliveira Vianna e Sérgio Buarque de Holanda*
}

\author{
ÂNGela De CAstro Gomes \\ Departamento de História da Universidade Federal Fluminense \\ Fundação Getúlio Vargas \\ angela.gomes@fgv.br
}

Resumo:

Oliveira Vianna e Sérgio Buarque de Holanda são dois clássicos do pensamento social brasileiro frequentemente tratados como antípodas. Este artigo tem como objetivo aproximar (e não comparar) os dois autores, trabalhando com dois conceitos-chave de suas obras: o de insolidarismo, marcante em vários textos de Oliveira Vianna e o de cordialidade, presente em Raízes do Brasil, de Sérgio Buarque. A intenção é demonstrar que tais conceitos, que ocupam uma posição de equivalência estrutural em suas obras, são construídos a partir de um diagnóstico sobre o Brasil que trabalha com um mesmo conjunto de elementos básicos, desembocando numa apreciação sobre o homem e a sociedade brasileiros surpreendentemente convergente.

Palavras chave:

Intelectuais; Pensamento social brasileiro; Insolidarismo; Cordialidade.

\section{Abstract:}

Oliveira Vianna and Sérgio Buarque de Holanda are two classics of the Brazilian social thinking, often treated as antipodes. This article aims to bring together (not to compare) the two authors, handling two key concepts of their works: "insolidarismo" (non-solidarism), evident in various texts of Oliveira Vianna and "cordialidade" (cordiality/goodwill), present in Raízes do Brasil, by Sérgio Buarque. The intention is to demonstrate that such concepts, which occupy a position of structural equivalence in their works, are constructed from a diagnosis of Brazil that works with the same set of basic elements, culminating in a surprisingly convergent consideration of the Brazilian man and society.

Keywords:

Keywords: Intellectuals; Brazilian social thinking; Non-solidarism; Cordiality/ /Goodwill.

* Este artigo resulta da adaptação do texto da conferência com o mesmo título proferida na FLUC, a 10 de Dezembro de 2010, no âmbito da unidade curricular Império e Pós-Colonialismo 3 (Curso de $3^{\circ}$ Ciclo em Altos Estudos em História e Curso de $3^{\circ}$ Ciclo em Linguagens e Heterodoxias: História, Poética e Práticas Sociais), leccionada pelos Profs. Doutores Fernando Catroga e João Paulo Avelãs Nunes. 


\section{Introdução}

Oliveira Vianna e Sérgio Buarque de Holanda são dois clássicos do pensamento social brasileiro, dois grandes intérpretes do Brasil, freqüentemente tratados como antípodas. Evidentemente, essa oposição construída entre eles não é "natural", tendo sido proposta e consolidada por meio da ação de muitos outros intelectuais, sobretudo a partir de meados do século XX, sendo sua maior referência um prefácio, que se tornou famoso, escrito em tom memorial, pelo crítico literário paulista Antônio Cândido, para o livro de Sérgio Buarque, Raízes do Brasil, cuja primeira edição é de 1936. Mas, é interessante remarcar, logo de início, que esses intelectuais se conheceram e travaram contatos "delicados" entre si, em momento em que a carreira política e intelectual de Oliveira Vianna decaía vertiginosamente, e a de Sérgio Buarque de Holanda ascendia e era crescentemente reconhecida.

Um exemplo paradigmático desse relacionamento, que indica o tipo de críticas que as interpretações de Oliveira Vianna passam a receber, particularmente desde a segunda metade dos anos 1940 e, ao mesmo tempo, a recuperação que seu pensamento começa a sofrer, a partir do fim dos anos 1970, é o depoimento do próprio Sérgio Buarque de Holanda, na "Apresentação" de seu livro Tentativas de mitologia. Publicado pela editora Perspectiva, em 1979, o primeiro de seus artigos, intitulado "Cultura e Política", que, segundo o autor, fora escrito em início de 1949, rememora suas leituras de Oliveira Vianna. Assim, publicado trinta anos depois de elaborado, em um contexto político e intelectual inteiramente diverso - porque Vianna havia falecido em 1951; porque o Brasil já vivera o golpe militar de 1964; porque o autoritarismo então implantado já ultrapassara seu momento mais duro, passando o país por um processo de "abertura" -, o artigo possibilita que seus leitores do fim dos anos 1970 tomem contato com as lembranças de Sérgio, nesse momento o mais aclamado historiador brasileiro, sobre o "esquecido e execrado" Oliveira Vianna. Portanto, é em tom memorial que dialoga com seus leitores:

"Relendo agora o estudo que abre este livro, dedicado a uma obra de Oliveira Vianna, chego por vezes a perguntar-me se a ênfase dada a enganos patentes, a flagrantes inconseqüências e a critérios anacrônicos, que se encontram nessa obra, não parecerão trair uma espécie de triunfalismo de censor bisonho, que se compraz em dar quinaus num autor consagrado e provecto. Haverá grande vantagem, por exemplo, em denunciar seu recurso constante a argumentos biológicos já caídos em um descrédito mortal ao tempo em que ele, Oliveira Vianna, ainda apelava para seus préstimos sempre que queria explicar os fundamentos de nossa sociedade e de nossa política? 
A resposta está nisto, que tais inconseqüências [...] estão longe de representar o alvo maior da minha crítica. $O$ alvo maior está em uma vasta construção jurídica e política, expressa nas leis trabalhistas, da era Vargas, a que ela pretende fornecer o necessário suporte científico" ${ }^{\text {. }}$

Nesse sentido, com a ajuda das reflexões de Sérgio Buarque de Holanda, é possível constatar os fortes deslizamentos políticos que a análise do pensamento político de Vianna provocava ainda em início da década de 1950. Era mais ao teórico do corporativismo que se combatia, do que ao intérprete da causas do "atraso" brasileiro. Mas, nem sempre foi assim... De toda a forma, pode-se dizer que os anos 1950 são tanto os da construção de uma figura mítica de Oliveira Vianna (reservado, autodidata etc), o que foi tarefa de seus admiradores, empreendida logo após a sua morte ${ }^{2}$; como os de destruição sistemática dessa mesma figura (racista, reacionário etc), o que se aprofundaria nos anos 1960. Uma trajetória de declínio, não casualmente alimentada pela eclosão de movimentos sociais de caráter político popular em inícios dessa década, bem como pela constatação da crescente força e violência do regime militar, que se instala em sua segunda metade. Assim, paradoxalmente, esse seria o tempo em que o interesse acadêmico pela questão das bases do autoritarismo no Brasil e das idéias de alguns de seus maiores pensadores, irá trazer Oliveira Vianna de volta (e não só ele, é claro), situando-o, em outra perspectiva, diante do olhar crítico de muitos historiadores e cientistas sociais. De fato, a fortuna crítica da obra de Oliveira Vianna e de Sérgio Buarque de Holanda, como não poderia deixar de ser, tem muito a ver com a trajetória pessoal e intelectual de ambos, mantendo também sólidos vínculos com as conjunturas políticas do Brasil e do mundo, o que os foi tornando quase duas faces de uma moeda.

Portanto, trabalhar com esses dois autores, de forma conjunta, não é nada usual e o exercício que se propõe neste artigo é, no mínimo, bastante heterodoxo, tendo sido recebido com muita desconfiança, nas primeiras vezes em que o

1 HOLANDA, 2001, pp. 8-9. O livro de Oliveira Vianna comentado e criticado no artigo é Instituições políticas brasileiras, Rio de Janeiro, José Olympio, 1949. Portanto, é bem provável que o texto de Sérgio tivesse sido escrito como uma espécie de resenha.

2 Uma imagem de Oliveira Vianna foi reforçada logo após sua morte por seus admiradores, todos intelectuais fluminenses, o que se materializa pela transformação de sua residência em Museu Casa, pela Lei 1.208 de 14 de junho de 1951. Anos depois, pelo Decreto n. 5.317, de 16 de abril de 1956, é transformada em Fundação Oliveira Vianna. Em 1975, passou a integrar a Fundação Estadual de Museus do Rio de Janeiro e, em 1980, a Fundação de Artes do Estado do Rio de Janeiro (Funarj). 
tornei público. ${ }^{3}$ Isso porque, tal exercício tem como objetivo aproximar (não se trata de comparar) esses dois autores, trabalhando com dois conceitos-chave, marcantes em suas obras.

O conceito, no caso de Oliveira Vianna, é o de insolidarismo, presente em praticamente todos os seus textos, mas proposto em seu grande e consagrado livro de estréia, Populações Meridionais do Brasil, de $1920,{ }^{4}$ e permanecendo estratégico até seu último livro, História social da economia capitalista no Brasil, cuja $1^{\text {a }}$ edição data de 1987: um livro inacabado e uma edição póstuma. ${ }^{5}$ No caso de Sérgio Buarque de Holanda, o conceito é o de cordialidade, central em Raízes do Brasil, cuja $1^{\text {a }}$ edição é de 1936, como se disse. A minha proposta é a de que esses conceitos ocupam uma posição de equivalência estrutural nos trabalhos desses autores. Ou seja, não se trata de minimizar as distinções existentes entre esses intelectuais, em particular as políticas - Oliveira Vianna foi um dos ideólogos do autoritarismo do Estado Novo e o Sérgio Buarque um liberal que lhe fez oposição -, nem de postular uma equivalência substantiva entre tais conceitos, ou seja, considerara que eles têm o mesmo sentido/ /significado. A intenção do exercício é demonstrar que tais conceitos são construídos a partir de um diagnóstico sobre o Brasil que trabalha com um mesmo conjunto de elementos básicos, desembocando numa apreciação sobre o homem e a sociedade brasileiros, surpreendentemente convergente. Isso porque, tais conceitos têm como fundamento análises sobre a importância do que os autores entendem ter sido o legado da experiência colonial portuguesa no Brasil.

Portanto, o que justifica trazer essas reflexões para um curso que tem como tema o colonialismo e o pós-colonialismo, principalmente considerando-se que não sou uma estudiosa do período colonial da História do Brasil, é o fato de, no pensamento desses dois grandes autores, ter-se concedido um lugar absolutamente crucial à experiência do colonialismo, que, segundo eles, teria deixado marcas profundas e duradouras na mentalidade/cultura brasileiras. Isto porque, o trabalho deles (e também de muitos outros intelectuais da época) está sendo entendido como um esforço para tornar intelegível, o que entendia

3 As reflexões deste artigo foram publicadas, em versões distintas por duas vezes. A primeira com o título "A dialética da tradição", Revista Brasileira de Ciências Sociais, ANPOCS, n. 12, 1990. A segunda, "Cheiro de terra", Revista de História da Biblioteca Nacional, 2006, em um dossiê dedicado aos 70 anos de Raízes do Brasil.

4 Estou trabalhando com a $7^{\mathrm{a}}$ edição de Populações meridionais do Brasil: populações rurais do centro-sul, Belo Horizonte/ Itatiaia; Niterói/ Eduff, 1987 (2 vols.).

5 Estou usando a $19^{\circ}$ edição de Raízes do Brasil, Rio de Janeiro, José Olympio, 1987 e a $1^{\text {a }}$ edição de História social da economia capitalista no Brasil, Belo Horizonte/Rio de Janeiro, Itatiaia/UFF, 1987. 
ser as características cruciais da realidade brasileira, com a intenção explícita de oferecer subsídios para a elaboração de projetos que visassem intervenções políticas modernizadoras. A eficácia de tal esforço, que implicava a permanente construção simbólica da identidade nacional, estava assim diretamente correlacionada às condições de plausibilidade das interpretações formuladas, o que só podia ser avaliado em função de uma congruência tanto com a realidade social sob análise, quanto com os paradigmas políticos e intelectuais vigentes em determinado momento.

No caso, o que se quer destacar é a enorme importância que é atribuída à experiência colonial brasileira, quer para entender as causas do atraso e das dificuldades para o país alcançar uma desejada modernidade; quer para situar, nessas mesmas dificuldades, algumas das razões para a existência de uma "solução alternativa" de desenvolvimento; um caminho verdadeiramente nacional e eficaz para se alcançar a modernidade. Além disso, no caso da produção de interpretações da realidade social, como as que estão em foco neste exercício, o que ocorre é que seus resultados são sempre apropriados de formas diversas por diferentes grupos sociais, o que os torna uma dimensão integrante e influente da própria realidade, circulando sob outros formatos em muitos outros tempos. ${ }^{6}$ Aliás, o que análises como esta demonstram, é que eram vários os projetos/caminhos existentes naquela primeira metade de século $\mathrm{XX}$, pois muitas eram as modernidades consideradas possíveis e desejáveis. Como nos ensina Alice, a do país da maravilhas, a saída depende sempre do lugar onde se deseja chegar.

\section{A montante antiliberal e o pensamento social brasileiro}

Oliveira Vianna e Sérgio Buarque de Holanda são homens de seu tempo, o que significa dizer autores cujo pensamento se configura, divulga e é reconhecido ainda no período que decorre dos anos de 1920 aos anos 1950 , e, no caso do segundo, se prolongando e consolidando na segunda metade do século XX. Dessa forma, dialogam com as tradições e paradigmas intelectuais que vigoram nesse tempo, debatendo, preferencialmente, com autores que são também atores políticos, dessa primeira metade do século. Aliás, é recorrente na literatura especializada assinalar-se a importância dos anos 1920/30 para a formação desses autores e para a formação das bases de uma matriz do

6 Esta circulação entre o trabalho intelectual de interpretação da realidade e sua apropriação e integração na própria sociedade pode ser traduzida pela idéia de dupla hermenêutica do sociólogo Anthony Giddens. O conceito de apropriação utilizado é do historiador Roger Chatier em vários de seus livros. 
pensamento social brasileiro, claramente antiliberal e moderna, com a qual eles terão que dialogar, aderindo, rejeitando ou negociando de alguma forma.

Os anos 1920/30 são, portanto, como sabemos, internacionalmente, aqueles do que se convencionou caracterizar como de montante do pensamento antiliberal. Se, grosso modo, até a Primeira Guerra Mundial o paradigma que dominava os projetos de modernização política das nações, orientava-se pela construção de um espaço público, no qual o poder do Estado - weberianamente impessoal e racional-legal -, se fundava em uma arquitetura institucional liberal, com Parlamento, eleições e partidos políticos, após o impacto desse conflito e entre suas vítimas, estava esse mesmo paradigma. Ou seja, esse referencial sofreria questionamentos radicais, o que situa o clima em que são elaboradas muitas das novas orientações que passarão a marcar o pensamento social brasileiro nas décadas subseqüentes. Correndo alguns riscos, pode-se dizer que, entre um grande número de intelectuais, nos quais se situa o próprio Oliveira Vianna, não se tratava mais de apontar a existência de condições adversas à vigência do modelo de Estado liberal, mas de afirmar sua impossibilidade e indesejabilidade de adaptação à realidade nacional brasileira.

Neste sentido, é tal paradigma que passa a sofrer as críticas de uma nova orientação científica, traduzida tanto pelos postulados de uma teoria elitista, que atacava as ficções políticas liberais, como pelos enunciados da teoria econômica Keynesiana, defensora de um intervencionismo econômico e social do Estado, até então inusitado. Assim, se permanecia de pé um ideal de autoridade racionallegal e de economia urbano-industrial, signos de uma sociedade moderna, os instrumentos operacionais, ou seja, os valores e as instituições políticas para construí-lo e materializá-lo, sofriam mudanças substanciais. Tais mudanças implicavam sempre em uma crítica à arquitetura liberal, de forma mais ou menos radical, conforme os exemplos europeus e o norte-americano, após a crise econômica de 1929, passavam a demonstrar. A idéia de igualdade liberal, fundada na eqüidade política do indivíduo/cidadão, portador de opinião e potencial eleitor, vai ser fortemente contestada, defendendo-se uma desigualdade natural dos seres humanos que, justamente por isso, não podiam ser tratados da mesma maneira pela Lei/Direito. Dessa forma, o modelo de cidadão liberal, até então definido como possível, mas, no caso do Brasil, ainda inexistente, tornava-se uma completa ficção, assim como os procedimentos e as instituições a ele associadas: eleições, voto, partidos políticos, parlamentos etc.

Apenas para que se tenha uma dimensão do compartilhamento que tais diretrizes antiliberais então alcançam, segundo Hobsbawn, entre o fim da Primeira e da Segunda Grande Guerra, o número de governos constitucionais sofreu um drástico recuo em todo mundo: nos anos 1920, eram 35; em 1938, 
passaram a ser 17; e, em 1944, restringiam-se a $12 .{ }^{7} \mathrm{Na}$ verdade, na Europa, pode-se dizer que apenas a Inglaterra não conviveu com um avanço significativo de forças políticas antiliberais, e a América foi um continente onde houve poucos exemplos de resistência: os EUA, o Canadá e o Uruguai, estão entre eles. Além desse indicador quantitativo, convém igualmente destacar, numa dimensão qualitativa, que as correntes antiliberais que ganhavam força vinham da direita do espectro político e tinham características muito distintas da direita "conservadora", até então conhecida. Como a literatura que trata do tema das organizações políticas e das ideologias tem assinalado, a "nova direita" que emerge nos anos 1920-30, se propõe a usar recursos organizacionais e a mobilizar valores e crenças de forma muito inovadora, aproximando-se mais do instrumental revolucionário utilizado pelo que então era identificado como "esquerda" (a despeito de sua diversidade), do que pelo que vinha sendo tradicionalmente usado pela "direita", razão porque os confrontos podiam ocorrer nessas duas direções.

O Brasil, por conseguinte, é apenas um dos países que alimentará essa montante internacional de antiliberalismo, inserindo-se em um grande conjunto de experiências que marcou o entre-guerras. A defesa do poder de intervenção do Estado e do avanço de sua governabilidade sobre a sociedade - algo que podemos considerar uma regularidade em sociedades de "modernização retardatária" -, contudo, não deve ser identificada como um mero sinônimo de defesa de Estado autoritário, forte e com poder concentrado no Executivo, como muito freqüentemente ocorre. Esforços empreendidos no terreno do ideário liberal, ainda existentes nos anos 1930, evidenciam as possibilidades de disjunção entre nacionalismo e defesa do intervencionismo estatal, de um lado,/ e propostas de centralização e autoritarismo do regime político, de outro.

De toda forma, a despeito da grande diversidade de análises produzidas por intelectuais que viveram no contexto dos anos 1920/1950, que comportavam opções teóricas e ideológicas bastante diferenciadas, existiu entre elas um ponto de convergência quanto à situação de atraso em que se encontrava o país. Para praticamente todos os que pensavam o Brasil, esse atraso se devia a um descolamento entre o que se chamava de "Brasil real" ou "realidade brasileira", e "Brasil legal" ou mundo das instituições, que supunha "governar" uma nação que, de fato, não existia. Nessa perspectiva, o grande desafio a ser enfrentado por nações coloniais como o Brasil, envolvia duas premissas. De um lado, o reconhecimento de um paradigma de política moderna, entendida como o

7 Eric Hobsbawn, Era dos extremos: o breve século XX (1914-1991), São Paulo, Companhia das Letras, 1995, p. 115. 
mundo dos cidadãos racionais e dos procedimentos públicos impessoais, mundo existente de fato nos países desenvolvidos. De outro lado, a necessidade de compreensão de uma realidade social que com ele se confrontava, pois fundava-se em padrões de autoridade tradicionais - personalizadas e irracionais -, que não podiam ser ignorados e menosprezados, sob pena de total insucesso.

Um problema que marcaria, por décadas, a vida e o debate políticos do país e que não está de todo encerrado. Essa dicotomia real/legal, então muito compartilhada, tinha, portanto, causas profundas, radicando-se no passado colonial brasileiro. A experiência colonial assume, dessa forma, um lugar estratégico no pensamento desses dois autores, sendo preciso remontar a essas "origens" - quase imemoriais, mas fundamentais - para se imaginar os dilemas do Brasil. De forma decisiva e resumida, para eles, a sociedade brasileira e a "mentalidade" que a dominava tinha cheiro de terra, não amava o trabalho, obedecia ao pai de família e nascera em Portugal.

\section{Oliveira Vianna e o insolidarismo como herança colonial}

Para Oliveira Vianna, o insolidarismo, que marcava há séculos a sociedade brasileira, condensava o diagnóstico das causas do atraso do Brasil. Tal formulação começou a ser elaborado no fim dos anos 1910. Um momento onde o mundo tentava se recuperar do cataclisma que fora a Primeira Guerra Mundial e, no Brasil, começavam a circular, com mais ênfase, explicações científicas de teor histórico-sociológico sobre as razões dos "males" do país, fossem eles sociais, políticos e culturais. É então, que o autor publica seu livro de estréia, Populações Meridionais do Brasil, pela Monteiro Lobato e Cia. (São Paulo, 1920). Nesse livro, voltando-se para as origens de nossa "formação", para o primeiro século de colonização, ele constrói um modelo interpretativo capaz de explicar porque, no Brasil, devido à nossa experiência colonial, não éramos capazes de construir formas/associações de solidariedade social modernas. Era esse passado histórico mais remoto do país que "continha" as razões sociológicas da falta de solidariedade vigente, da incapacidade de organização autônoma da população brasileira, da ausência de opinião pública, enfim, de tudo que possibilitava a emergência de uma moderna sociedade urbano-industrial.

Nesse sentido e em contraposição a um discurso otimista ou "ufanista" sobre o futuro do Brasil, , começava a se cristalizar uma versão mais "realista",

8 O ufanismo tornou-se uma designação para identificar uma visão otimista sobre o futuro do Brasil, sobretudo devido a suas belezas e riquezas naturais. Tal categoria derivou de um famoso livro, escrito para crianças, Por que me ufano de meu país, de autoria do Conde Afonso 
que identificava um conjunto de "males" (falta de saúde, educação, opinião pública etc), todos eles sintetizados na inexistência de formas de solidariedade social e, em decorrência, de uma sociedade e de um governo modernos. Ou seja, nesse diagnóstico, o insolidarismo torna-se uma verdadeira chave mental, capaz de explicar a complexidade, a longevidade e a profundidade dos problemas brasileiros. Transforma-se, assim, em um dos conceitos mais estratégicos de um discurso político sobre o "atraso" do Brasil, presente na academia e na sociedade em geral (imprensa, senso comum), que só fará crescer e se difundir, desde os anos 1920. Recorrendo a um dos estudiosos de Oliveira Vianna, Luiz de Castro Faria, o insolidarismo é uma dessas categorias que permitem classificar o autor como um "fundador de discursividades". Isto é, como alguém cujas formulações são especialmente úteis para se ter acesso aos quadros mentais de uma época e à conformação de uma cultura política que entende o Brasil como desprovido, quase ontologicamente, de condições históricas para o desenvolvimento de formas de organização social modernas; de formas de ação coletiva, no vocabulário da Ciência Política contemporânea.

Segundo Oliveira Vianna, as relações sociais existentes no país, haviam se desenvolvido tendo como base o grande domínio rural, fincado na imensidão do território tropical: "Nós somos o latifúndio. Ora, o latifúndio isola o homem; o dissemina; o absorve; é essencialmente antiurbano". Portanto, o ruralismo e o escravismo de nossa formação colonial, demonstrando bem a força dos determinismos geográficos e raciais no pensamento do autor, eram os responsáveis por um padrão de sociabilidade centrado na família e na autoridade pessoal do grande proprietário. Os conceitos que o autor elabora para a compreensão desse modelo de sociedade são os de "função simplificadora do grande domínio rural e o de espírito de clã". O primeiro apontava para a independência e auto-suficiência dos senhores de terra e escravos, que "simplificavam" toda nossa estrutura social.Assim, dificultavam o desenvolvimento de atividades comerciais e industriais, impedindo quaisquer outros associativismos que escapassem à família e às relações de dependência pessoal face ao patriarca. O segundo, de "espírito de clã", ao mesmo tempo que protegia o homem rural da falta de qualquer outra autoridade efetiva, inclusive a do Estado português, bloqueava o "espírito corporativo/associativo" que só podia se afirmar no ambiente urbano e que, por isso, não se formara no Brasil.

Dessa maneira, era a vida na grande família a base e a origem de dois graves problemas da política brasileira: o caudilhismo e o personalismo.

Celso, membro do Instituto Histórico e Geográfico Brasileiro, por ocasião das comemorações do Centenário do Descobrimento em 1900. 
Um tipo de autoridade que abarcava vínculos políticos e sociais e que recorria à fidelidade e à afetividade, orientando-se, por conseguinte, por valores não apenas estritamente materiais e utilitários, o que era um diferencial que podia ser muito importante. Para enfrentar a força do caudilhismo, que era sempre uma ameaça de desintegração territorial e social do país, só um poder centralizador forte - metropolitano ou nacional -, que agisse como promotor da paz e da proteção dos cidadãos. Para Oliveira Vianna, a realidade do caudilhismo acabara por inverter o sentido mais conhecido do poder central que, de autoridade absolutista e opressora das liberdades, tornava-se o único meio de construção de um Estado moderno. Isto é, tornava-se um Estado orientado por procedimentos racionais/burocáticos, mas igualmente próximo e conhecedor da realidade nacional. Só esse novo Estado - um Estado forte -, poderia neutralizar o caudilhismo, expresso nos localismos e personalismos, bem como o "artificialismo jurídico", traduzido em leis que não funcionavam ("não pegavam"), porque não consideravam nossas tradições históricas, construídas lenta e solidamente, desde os tempos coloniais.

Porém, se o grande domínio isolava o homem, sendo o berço do "espírito de clã", do caudilhismo e de uma ética de rejeição ao trabalho (feito por escravos e não homens livres), era ele também o berço de relações sociais fundadas em sentimentos, que bloqueavam o frio espírito do lucro material e da ambição sem limites, que caracterizava sociedades como a norte-americana. Era esse "espírito do pré-capitalismo", existente na sociedade brasileira, e cujo tom principal era a afetividade, que produzia, por exemplo, uma aproximação entre os "distantes hierárquicos", pelo compadrio ou pela religiosidade, entre outros fatores, ainda muito presentes nos meios rurais mesmo em meados do século XX.

Lentamente construída e refinada por séculos, essa mentalidade - insolidária e emotiva - emergia, ao mesmo tempo, como um obstáculo a ser vencido e uma vantagem a ser explorada. No Brasil, para Oliveira Vianna, não se construíra, como nos EUA, uma total e maléfica subordinação dos interesses sociais e políticos aos interesses econômicos/ materiais, ao lucro, ao "bezerro de ouro", como menciona. Nesses termos e em uma sofisticada operação intelectual, o "Brasil real" não era um "mal absoluto"; não estava inteiramente desqualificado. Ao contrário, guardava algumas vantagens poderosas, porque era com esse "Brasil real" que se poderia chegar a um projeto político eficiente, uma vez que adequado à nossa singularidade, à nossa realidade nacional. Um projeto que Oliveira Vianna se dedicará a construir nos anos 1930/40, e que pode ser identificado (mas não analisado aqui), como o de um Estado corporativo, autoritário e autenticamente nacional. 


\section{A "cordialidade" como marca de brasilidade}

Uma das razões que torna Raízes do Brasil um livro particularmente estimulante é o fato de não ser um texto fechado. Toda a análise do autor conflui para um dilema muito nítido, para o qual não se dá solução acabada. Tal impasse, entretanto, não chega a ser trágico, uma vez que a análise nos acena com a possibilidade de transformar nossa própria dificuldade em vantagem. Já que tal dificuldade não era um mal estrutural, nem uma fatalidade insuperável, tornava-se viável pensar e tentar uma saída que fosse original e positiva. Este dilema, em Sérgio Buarque de Holanda, pode ser percebido através do conceito de cordialidade, que não é formulado como uma essência própria/ /inata ao homem brasileiro, mas também como uma mentalidade. Quer dizer, como uma característica cultural da sociedade brasileira construída ao longo de sua história. O homem cordial seria, assim, na verdade, o produto síntese da herança colonial portuguesa, responsável pela gestação de uma sociedade onde dominam relações sociais pessoalizadas, afetivas, particularistas e clientelistas. A cordialidade, nossa marca registrada, seria, ao mesmo tempo, um obstáculo e uma proteção aos males da modernidade, pois esta também os possuía. Obstáculo, uma vez que bloqueava a instauração de um verdadeiro espaço público democrático onde devem dominar relações sociais impessoais. Mas também uma proteção, pois podia evitar os excessos de uma sociedade moderna ultra-racionalizada, burocratizada, impessoal e orientada apenas por interesses/lucros materiais.

Em sua análise, Sérgio Buarque vai sustentar e demonstrar que a cordialidade é uma realização da cultura ibérica. São as características desta cultura que permitem compreender a exploração colonial estabelecida no Brasil e, em decorrência, a herança do ruralismo e do escravismo que marca a sociedade brasileira: a colônia era um projeto da metrópole e, não há, para ambos os autores, "bons" colonizadores. A transfiguração da cordialidade é, assim, a superação da herança portuguesa, abrindo portas a um novo e original caminho, americano, no dizer do autor.

Para Sérgio Buarque de Holanda, de maneira sucinta e certamente esquemática, é essa herança que explica o que ele está conceituando como cordialidade. Em primeiro lugar, porque na Península Ibérica se desenvolveu o que chama de "cultura da personalidade", uma forma radical de individualismo em que imperam os sentimentos de responsabilidade, de dignidade pessoal, enfim, de honra. Essa forma própria de viver o individualismo suscitou desdobramentos importantes no que se refere, por exemplo, ao princípio hierárquico que, para esse autor, nunca chegou a ser impermeável e rigoroso na nobreza 
lusitana, produzindo uma sociedade caracterizada pela plasticidade e capaz de assimilar novas idéias, sem transformar inteiramente seu tradicional modo de pensar e agir. Em segundo lugar, é devido a essa "cultura da personalidade", que sustenta uma vivência específica do livre-arbítrio, que é tão difícil, entre os portugueses (e brasileiros), o desenvolvimento de formas associativas modernas, que propiciem coesão entre diversos grupos da sociedade. É essa cultura, portanto, um dos grandes óbices ao espírito de organização espontânea, que seria tão característico de povos protestantes. O tema da autoridade, do Estado centralizado e forte, está também situado (mas não tanto justificado), por força da ausência de formas de agregação social de outra natureza. Assim, se o livre-arbítrio é um valor radical, qualquer atividade humana que implique submissão a uma lógica distinta da vontade individual é entendida como uma agressão. Esta é, para o autor, a raiz da "invencível repulsa" a toda a moral fundada no trabalho, em especial no manual e mecânico. É também o maior obstáculo para a construção de redes associativas que têm nas relações de interesses materiais uma razão fundamental e legítima.

Todas essas características tiveram, para Sérgio Buarque de Holanda, uma influência decisiva no tipo de exploração colonial experimentada pelo Brasil, que seguiu a "ética da aventura": uma ocupação do território que ignorou projetos de mais longo prazo. O ruralismo, que é a base do Brasil colonial, traduzido pela exploração da grande propriedade com escravos, origina-se dessa "ética da aventura", que cultiva a bravura e a audácia, mas igualmente a imprevidência, a instabilidade e a ociosidade. A grande propriedade, autônoma e isolada, e a família colonial são seus núcleos principais. E, como esse modelo de relações sociais está centrado na autoridade patriarcal, indisputada e pessoalizada, a solidariedade que existe e a que se nega, passa sempre pelos sentimentos. Dessa forma, no Brasil, há como que um veto à lógica impessoal de relações sociais, identificada como fria, "interesseira" e, até por isso, imoral. No Brasil, por obra do legado colonial português, tem vigência uma outra lógica de relações sociais, ou seja, uma outra mentalidade ou cultura, orientada por sentimentos, que é pessoal, imaterial e moral.

\section{O Brasil em busca de "sua" modernidade}

Como se vê, os dois autores, a despeito de terem propósitos políticos e intelectuais muito distintos, produzem suas reflexões a partir de um diagnóstico histórico-sociológico que tem como questão fundamental o processo de colonização. Tanto Sérgio Buarque de Holanda como Oliveira Vianna 
(e muitos outros), ao realizarem um esforço para compreender a sociedade brasileira e, especialmente, as causas de seu atraso, partem da interrogação sobre a existência ou não de uma verdadeira mentalidade e/ou cultura nacional. Se ela existisse, suas características só poderiam ser traçadas e compreendidas a partir da experiência da colonização portuguesa, o que os remete ao estudo dos processos de ocupação territorial e às questões da grande propriedade e do trabalho escravo. O eixo básico de análise de ambos articula a tradição rural escravista brasileira, às raízes mais profundas da sociedade, com suas formas de pensar e sentir, social e politicamente.

As convergências entre os elementos básicos de análise em Sérgio Buarque de Holanda e Oliveira Vianna não deixam de surpreender. Além disso, tanto um como o outro, não nos dão propriamente uma resposta, uma fórmula que permita resolver a tensão que suas análises produzem. Em ambos, pode-se assinalar uma clara percepção de um processo de mudança social, instalado no Brasil a partir de 1888, com a Abolição, que se intensificou com a Primeira Guerra e a Revolução de 1930. Um processo muito importante, mas que não é tão drástico nem tão violento. Tais características, contudo, não o tornam menos desejado ou menos preocupante. O que fica claro é que, no Brasil, para os autores, processos de transformação social têm sempre sólidos pontos de apoio em nossas mais profundas tradições culturais, com destaque as vindas do período colonial.

Mas seria prudente concluir dizendo que, a despeito de as análises dos dois autores conduzirem a pontos muito semelhantes, o que ilustra a fecundidade e força das categorias com que trabalham e que marcam o campo intelectual de uma época, suas perspectivas permanecem distintas. Sérgio Buarque quer, fundamentalmente, compreender a sociedade brasileira; por isso, vai às "raízes" culturais de nossa formação e acaba chegando à política. Oliveira Vianna quer, principalmente, organizar o "Brasil real"; para isso, precisa fundar sua reflexão política em uma análise histórico-sociológica, conforme modelo então vigente. Tais percursos não são casuais e certamente esclarecem a maior margem de liberdade deixada por Sérgio Buarque e o misto de admiração e angústia provocado por Oliveira Vianna.

\section{Bibliografia}

CÂNDIDO, Antônio (org.), Sérgio Buarque de Holanda e o Brasil, São Paulo, Fundação Perseu Abramo, 1998.

BASTOS, Élide Rugai e MORAES, João Quartim de (orgs.), O pensamento de Oliveira Vianna, Campinas, Editora da UNICAMP, 1993. 
BRASIL Jr., Antônio da Silveira, Uma sociologia brasileira da ação coletiva: Oliveira Vianna e Evaristo de Moraes Filho, ICHF/UFRJ, 2007 (Dissertação de Mestrado).

BRESCIANI, Maria Stella M. O charme da ciência e a sedução da objetividade: Oliveira Vianna entre intérpretes do Brasil, São Paulo, Unesp, 2005.

FARIA, Luiz de Castro. Oliveira Vianna: de saquarema à Alameda São Boaventura, 41, Niterói: o autor, os livros e a obra, Rio de Janeiro, Relume-Dumará, 2002.

GOMES, Ângela de Castro, A invenção do trabalhismo, Rio de Janeiro, Ed. FGV, 2005.

GOMES, Ângela de Castro, Cidadania e direitos do trabalho, Rio de Janeiro, Ed. Zahar, 2002.

GOMES, Ângela de Castro, "A política brasileira em busca da modernidade: na fronteira do público e privado", NOVAIS, Fernando e SCHWARTZ, Lilia (orgs.), História da vida privada no Brasil, São Paulo, Cia. Das Letras, 1998, pp. 489-558.

GOMES, Ângela de Castro, "A ética católica e o espírito do pré-capitalismo". Ciência Hoje, Rio de Janeiro, SBPC, vol. 9, n. 52, Abril de 1989, pp. 23-28. GOMES, Ângela de Castro, "A dialética da tradição", Revista Brasileira de Ciências Sociais, São Paulo, Vértice, vol. 5, nº 12, 1990, pp. 15-27.

HOLANDA, Sérgio Buarque de, Tentativas de mitologia, São Paulo, Ed. Perspectiva, 1979 (pp. 37-60).

HOLANDA, Sérgio Buarque de, Raizes do Brasil, Rio de Janeiro, José Olympio, $1987,19^{\circ}$ ed. (1 $1^{\text {a }}$ ed. 1936$)$.

REIS, Elisa M. P., «O estado nacional como ideologia: o caso brasileiro», Estudos Históricos, Rio de Janeiro, vol. 1, nº 2, 1988, pp. 187-203.

VIANA, Oliveira, Populações meridionais do Brasil: populações rurais do centro-sul, Belo Horizonte/Itatiaia, Niterói/EDUFF, 1987, $7^{\text {a }}$ ed. $\left(1^{\text {a }}\right.$ ed. 1918).

VIANA, Oliveira, "O idealismo da Constituição", CARDOSO, Vicente Licínio (org), À margem da história da República, Brasília, Ed. UnB, 1981.

VIANA, Oliveira, História Social da Economia Capitalista no Brasil, 2 volumes, Belo Horizonte, Itatiaia; Niterói, Eduff, 1987. 